\title{
Tuturan Melarang dalam Komik Yotsubato Karya Kiyohiko Azuma
}

\author{
I Komang Triadi Merta Yasa*, Ni Made Andry Anita Dewi, Ni Luh Kade Yuliani Giri \\ Program Studi Sastra Jepang, Fakultas Ilmu Budaya, Universitas Udayana \\ [triadimertayasa@gmail.com], [andry_anita@unud.ac.id] [yuliani_giri@unud.ac.id]
}

\begin{abstract}
The research entitled "Speech of Prohibition in Comic Yotsubato by Kiyohiko Azuma" is aimed to identify various form of speech of prohibition and the factors behind the use of the said speech in the comic Yotsubato by Kiyohiko Azuma. This research applied the theory of speech acts by Wijana (1996) and level of politeness factors according to Mizutani and Mizutani (1987). The method of collecting data used in the research is attentive observation method, which is done by observing the speech in the comic. Afterwards, the obtained data is noted by applying note-taking technique. The data analysis is done by using pragmatic identity method. Later on, in the data presentation, informal method is used. The result of the analysis indicates that in the comic Yotsubato, found 9 data that categorized as direct speech acts of prohibition and 7 data that categorized as indirect speech acts of prohibition. Then, there are 4 factors behind the use of the speech acts of prohibition in the comic Yatsubato, namely 1) familiarity factors; 2) age; 3) social distance; and 4) gender.
\end{abstract}

Keywords: speech acts, prohibition, politeness

\begin{abstract}
Abstrak
Penelitian ini berjudul "Tuturan Melarang dalam Komik Yotsubato Karya Kiyohiko Azuma". Tujuan penelitian ini yaitu untuk mengetahui bentuk-bentuk tuturan melarang serta faktor yang melatarbelakangi penggunaannya dalam komik Yotsubato karya Kiyohiko Azuma. Penelitian ini menggunakan teori tindak tutur menurut Wijana (1996) serta faktor penentu tingkat kesantunan menurut Mizutani dan Mizutani(1987). Metode pengumpulan data yang digunakan pada penelitian ini adalah metode simak yaitu dengan menyimak tuturan dalam komik. Kemudian data yang diperoleh dilanjutkan dengan teknik catat. Metode yang digunakan pada analisis data yaitu metode padan pragmatik. Selanjutnya, dalam penyajian hasil analisis data digunakan metode informal. Hasil analisis menunjukkan bahwa dalam komik Yotsubato ditemukan 9 data yang digolongkan ke dalam tindak tutur melarang langsung dan 7 data yang digolongkan ke dalam tindak tutur melarang tidak langsung. Kemudian, ditemukan 4 faktor yang melatarbelakangi penggunaan bentuk tindak tutur melarang dalam komik Yotsubato, yaitu 1) tingkat keakraban; 2) usia; 3) hubungan sosial; dan 4) jenis kelamin.
\end{abstract}

Kata Kunci: Tindak tutur, Melarang, Kesantunan 


\section{Latar Belakang}

Tindak tutur melarang adalah tindakan mengujarkan tuturan untuk memengaruhi seseorang agar tidak melakukan sesuatu. Gunarwan (2007: 78) menyatakan bahwa tindak tutur melarang merupakan tindakan mengeluarkan kata-kata atau tuturan agar seseorang tidak melakukan sesuatu. Tindak tutur melarang dapat disampaikan secara langsung maupun tidak langsung.

Tindak tutur melarang langsung dalam bahasa Jepang ditandai dengan beberapa bentuk. Iori (2000:161) menyatakan bahwa tindak tutur melarang langsung, seperti yang ditandai dengan penggunaan ungkapan larangan $\sim n a, \sim t e$ wa dame, te wa ikemasen dan naide kudasai, pada umumnya digunakan oleh penutur yang berkedudukan lebih tinggi terhadap mitra tutur yang berkedudukan lebih rendah. Selanjutnya, untuk tindak tutur melarang tidak langsung dapat dilihat dari ketidaksesuaian antara modus tuturan dengan maksud yang ingin disampaikan. Bila larangan disampaikan dengan menggunakan kalimat tanya atau kalimat berita, maka kalimat tersebut dapat dikategorikan sebagai tindak tutur melarang tidak langsung.

Penutur harus memerhatikan latar belakang mitra tutur ketika menggunakan tuturan melarang agar dapat memilih tuturan yang tepat. Misalnya ketika sedang bertutur kepada mitra tutur yang memiliki usia lebih tua, penutur tentunya harus menggunakan tuturan yang lebih sopan. Berdasarkan uraian tersebut, memahami bentuk tuturan melarang beserta faktor yang melatarbelakangi penggunaannya adalah hal yang penting guna menambah wawasan dalam bidang kebahasaan. Penelitian mengenai tindak tutur melarang dalam bahasa Jepang telah dilakukan sebelumnya, yaitu penelitian oleh Satria (2018), Lestari (2017) dan Novitayanti (2011). Namun, dengan hasil kajian yang berbeda.

\section{Pokok Permasalahan}

Berdasarkan latar belakang yang telah diuraikan sebelumnya, maka dapat dirumuskan beberapa masalah sebagai berikut.

a. Bagaimanakah bentuk tuturan melarang yang digunakan oleh tokoh-tokoh dalam komik Yotsubato karya Kiyohiko Azuma?

b. Bagaimanakah faktor yang melatarbelakangi penggunaan bentuk tuturan melarang dalam komik Yotsubato karya Kiyohiko Azuma? 


\section{Tujuan Penelitian}

Secara umum penelitian ini bertujuan untuk menambah wawasan pada bidang linguistik mengenai kajian pragmatik khususnya mengenai tuturan melarang dalam bahasa Jepang. Selain itu, secara khusus penelitian ini bertujuan untuk mengetahui bentuk tuturan melarang beserta faktor yang melatarbelakangi penggunaannya dalam komik Yotsubato karya Kiyohiko Azuma.

\section{Metode Penelitian}

Adapun metode yang digunakan pada penelitian ini ialah, pada tahap pengumpulan data digunakan metode simak dan teknik catat oleh Sudaryanto (1993). Bentuk tuturan melarang dianalisis dengan teori tindak tutur yang disesuaikan dengan pendapat Wijana (1996). Sementara faktor yang melatarbelakangi penggunaan bentuk tuturan melarang dianalisis dengan teori faktor tingkat kesantunan oleh Mizutani dan Mizutani (1987). Metode yang digunakan pada tahap analisis data adalah metode padan dengan pendekatan pragmatik oleh Sudaryanto (1993). Kemudian, pada penyajian hasil analisis data digunakan metode informal oleh Mahsun (2007).

\section{Hasil dan Pembahasan}

\subsection{Bentuk Tindak Tutur Melarang dan Faktor yang Melatarbelakangi Penggunaannya}

Berdasarkan hasil analisis tindak tutur melarang, ditemukan 2 bentuk tindak tutur melarang yaitu tindak tutur melarang langsung dan tindak tutur melarang tidak langsung. Sementara itu, ditemukan pula 4 faktor yang melatarbelakangi penggunaan bentuk tindak tutur melarang. Faktor-faktor tersebut ialah faktor tingkat keakraban, usia, hubungan sosial, dan jenis kelamin.

\subsubsection{Tindak Tutur Melarang Langsung}

(1)

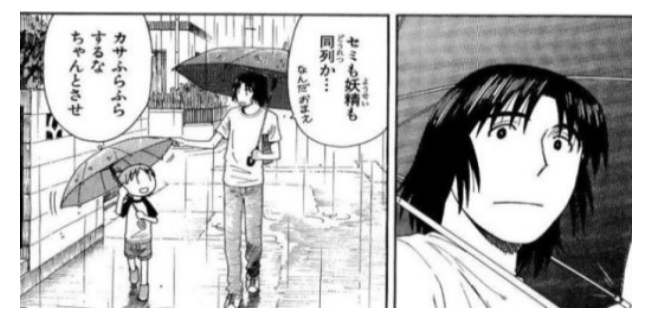




$\begin{array}{ll}\text { こいわい } & : \text { つつくぼうしセミで残念だったな。 } \\ \text { よつば } & : \text { なんで ?よつばセミすき。 } \\ \text { こいわい } & : \text { セミも妖精も同列か... カサふらふらするな ! ちやんとさせ。 } \\ \text { Koiwai } & : \text { Tsuku-tsuku boushi semi de zannen data na. } \\ \text { Yotsuba } & : \text { Nande? Yotsuba semi suki. } \\ \text { Koiwai } & \text { : Semi mo yousei mo douretsu ka... } \\ & \text { Kasa fura-fura suru na!Chanto sase. } \\ & \\ \text { Koiwai } & \text { : Sayang ya, kalau ternyata tsuku-tsuku boushi itu tonggeret. } \\ \text { Yotsuba } & \text { : Memangnya kenapa? Yotsuba suka tonggeret kok. } \\ \text { Koiwai } & \text { Tonggeret dan peri ituposisinya sama saja ya? Payungnya jangan } \\ & \text { diputar-putar! Pegang yangbenar! }\end{array}$

Tuturan pada data (1) merupakan tuturan antara Koiwai (penutur) dengan Yotsuba (mitra tutur) yang terjadi di tengah jalan. Pada saat itu, Yotsuba memainkan payung yang ia gunakan dengan memutar-mutarkan payung tersebut. Koiwai menjadi kesal melihat perbuatan itu. Ia kemudian mengujarkan kasa fura-fura suru na 'payungnya jangan diputar-putar!' kepada Yotsuba.

Tuturan kasa fura-fura suru na merupakan tindak tutur melarang langsung yang ditandai dengan penggunaan ungkapan larangan $\sim \boldsymbol{n a}$. Ungkapan larangan $\sim n \boldsymbol{a}$ merupakan penanda larangan yang berarti ‘jangan'. Ungkapan ini umumnya digunakan oleh kaum pria pada percakapan yang tidak formal (Makino dan Tsutsui, 1984: 266). Berdasarkan pernyataan tersebut, dapat dilihat dengan jelas bahwa tuturan kasa furafura suru na merupakan bentuk tindak tutur melarang langsung. Ungkapan larangan $\sim n a$ bermakna melarang apabila di depan penanda larangan $n a$ terdapat kata kerja bentuk kamus. Kata kerja bentuk kamus pada tuturan fura-fura suru na, adalah kata kerja furafura suru. Kata kerja fura-fura suru termasuk ke dalam kata kerja golongan III yang memiliki arti 'memutar-mutar' sehingga kata kerja bentuk kamus fura-fura suru dilekatkan dengan penanda larangan $n a$, artinya menjadi 'jangan diputar-putar'.

Faktor yang melatarbelakangi penggunaan tindak tutur melarang langsung pada data (1) adalah faktor tingkat keakraban, usia, hubungan sosial, dan jenis kelamin. Koiwai dan Yotsuba memiliki hubungan yang sangat akrab karena Yotsuba adalah anaknya sendiri. Mizutani dan Mizutani (1987: 4) menyatakan bahwa ketika orang Jepang melarang mitra tuturnya untuk melakukan sesuatu, ia akan menggunakan tuturan 
yang tidak formal atau tuturan langsung apabila terdapat hubungan akrab antara mereka. Faktor selanjutnya adalah faktor usia. Koiwai merupakan ayah dari Yotsuba, sehingga tentu saja Koiwai memiliki usia yang lebih tua daripada Yotsuba. Perbedaan usia antara mereka mengakibatkan penutur dapat menggunakan tuturan melarang langsung (Mizutani dan Mizutani, 1987: 4). Kemudian, hubungan sosial antara mereka juga memengaruhi penutur dalam menggunakan tuturan melarang langsung. Koiwai adalah ayah dari Yotsuba. Sudah sewajarnya seorang ayah dapat melarang anaknya secara langsung. Mizutani dan Mizutani (1987: 6) menyatakan bahwa secara umum mereka yang berstatus lebih tinggi, seperti atasan, pelanggan, dan orang tua, dapat menggunakan tuturan melarang langsung kepada mitra tutur yang berstatus lebih rendah. Selanjutnya, jika dilihat dari jenis kelamin penutur, Koiwai adalah seorang lakilaki. Makino dan Tsutsui (1984: 266) menyatakan bahwa ungkapan larangan $~ n a$ memiliki nuansa larangan yang keras dan umumnya digunakan oleh kaum pria pada percakapan yang tidak formal. Selain itu, Okamoto (2004: 46) menyatakan bahwa lakilaki pada masyarakat Jepang menggunakan ragam bahasa formal lebih sedikit daripada kaum wanita. Terdapat beberapa situasi ketika lelaki menggunakan ragam bahasa formal secara ekstensif.

(2)

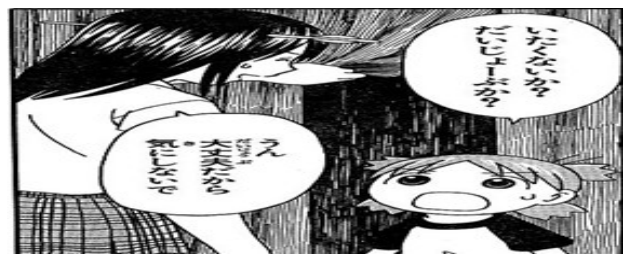

$\begin{array}{ll}\text { よつば } & : \text { あたまなんかささってる. . . } \\ \text { 高校生 } & : \text { うんはい、入ってください。 } \\ \text { よつば } & : \text { いたくないか ?だいじょうぶか ? } \\ \text { 高校生 } & : \text { うん。大丈夫だから、気にしないで。 } \\ \text { Yotsuba } & : \text { Atama nanka sasatteru... } \\ \text { Kōkōsei } & : \text { Un. Hai, haitte kudasai. } \\ \text { Yotsuba } & \text { : Itakunai ka? Daijobu ka? } \\ \text { Kōkōsei } & \text { : Un. Daijōbu dakara, ki ni shinaide. }\end{array}$




$\begin{array}{ll}\text { Yotsuba } & \text { : Kepala kakak tertusuk sesuatu. } \\ \text { Siswa SMA } & \text { : Iya, benar. Silahkan masuk! } \\ \text { Yotsuba } & \text { : apa tidak sakit? Tidak apa-apa kah? } \\ \text { Siswa SMA } & \text { : Iya. Aku baik-baik saja, jadi jangan dipikirkan! }\end{array}$

Tuturan pada data (2) merupakan tuturan antara siswa SMA (penutur) dengan Yotsuba (mitra tutur) ketika Yotsuba mengunjungi rumah hantu pada festival yang terdapat di sekolah Fūka. Saat Yotsuba mengunjungi rumah hantu itu ia merasa kasihan melihat siswa SMA penjaga rumah hantu tertusuk oleh anak panah. Yotsuba tidak mengetahui bahwa anak panah tersebut adalah anak panah mainan. Melihat Yotsuba yang mengkhawatirkan dirinya, siswa SMA tersebut mengujarkan daijōbu dakara, ki ni shinaide 'Aku baik-baik saja, jadi jangan dipikirkan!' kepada Yotsuba.

Tuturan ki ni shinaide kudasai pada data (2) merupakan tindak tutur melarang langsung yang ditunjukkan dengan penggunaan ungkapan melarang naide 'jangan'. Makino dan Tsutsui (1984: 210) menyatakan bahwa ungkapan naide merupakan bentuk nonformal dari naide kudasai yang digunakan untuk menyatakan larangan secara halus, sehingga tuturan ki ni shinaide dikategorikan sebagai bentuk tindak tutur melarang langsung. Penggunaan ungkapan naide dengan cara mengubah kata kerja bentuk kamus ke dalam kata kerja bentuk nai (nai-kei). Kata kerja bentuk kamus pada tuturan ki ni shinaide kudasai adalah ki ni suru yang artinya 'memperdulikan'. Kata kerja bentuk kamus ki ni suru kemudian mengalami konjugasi ke dalam kata kerja bentuk nai menjadi ki ni shi. Lalu kata kerja ki ni shi dilekatkan dengan naide, sehingga menjadi ki ni shinaide 'jangan dipikirkan'.

Faktor yang melatarbelakangi penggunaan tindak tutur melarang langsung pada data (2) adalah faktor usia dan jenis kelamin. Usia penutur lebih tua daripada mitra tutur yaitu penutur merupakan seorang siswa SMA sedangkan mitra tutur masih belum bersekolah. Hal tersebut menyebabkan Siswa SMA dapat menggunakan tindak tutur melarang langsung yang ditunjukkan dengan penggunaan ungkapan naide kepada Yotsuba. Selanjutnya, dilihat dari segi jenis kelamin, siswa SMA tersebut merupakan seorang wanita sehingga untuk memperhalus larangannya ia menggunakan ungkapan naide yang bernuansa larangan halus. Penggunaan ungkapan naide oleh penutur yang berjenis kelamin wanita juga diperkuat oleh pendapat dari Makino dan Tsutsui (1984) 
yang menyatakan bahwa pelesapan kudasai pada ungkapan naide (kudasai) biasanya digunakan oleh kaum wanita pada situasi yang tidak formal.

\subsubsection{Tindak Tutur Melarang Tidak Langsung}

(3)
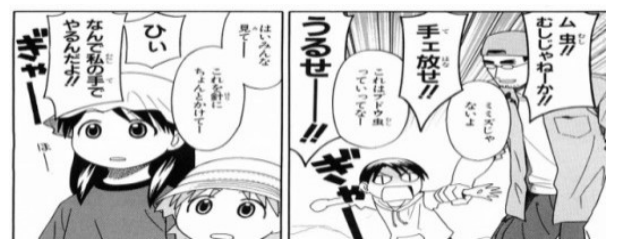

$\begin{array}{ll}\text { みうら } & : \text { ム虫！！ } \\ \text { ジュンボ } & : \text { ミミズじやないよ。 } \\ \text { みうら } & : \text { 手はなせ! ! } \\ \text { ジュンボ } & : \text { これはブドウ中っていつてな。 } \\ \text { みうら } & : \text { うさ! ! } \\ \text { ジュンボ } & : \text { はい、みんな見て。これを針にちょんとかけて。 } \\ \text { みうら } & : \text { ひい。なんで私の手でやるんだよ。 } \\ \text { Miura } & : \text { Mu mushi!! } \\ \text { Junbo } & : \text { Mimizu janai yo. } \\ \text { Miura } & : \text { Te hanase!! } \\ \text { Junbo } & : \text { Kore wa budou mushi tte itte na. } \\ \text { Miura } & : \text { Uruse!! } \\ \text { Junbo } & : \text { Hai, minna mite. Kore wo hari ni chonto kakete. } \\ \text { Miura } & : \text { Hii. Nande watashi no te de yarunda yo. }\end{array}$

(Yotsubato volume 4, 2005:42)
Miura
: Se, serangga!!
Jumbo
Ini bukan cacing tanah ya.
Miura
: Singkirkan dari tangan ku!!
Jumbo
Ini biasanya disebut dengan budou mushi.
Miura
: Diam kau!!
Jumbo
: Semuanya perhatikan! Kaitkan umpannya ke kail seperti ini!
Miura
: Hiii. Kenapa kau memperagakannya degan tangan ku!!

Tuturan pada data (3) merupakan tuturan antara Miura (penutur) dengan Jumbo (mitra tutur) yang terjadi di sungai pada saat Jumbo mengajarkan Miura, Ena, dan Yotsuba cara memasang umpan pada kail pancing. Jumbo mengenggam tangan Miura untuk memperagakan cara memasang umpan secara langsung. Setelah itu, ia meletakkan ulat serangga yang akan digunakan sebagai umpan di tangan Miura. Melihat 
hal tersebut, Miura langsung ketakutan dan menyuruh Jumbo untuk menyingkirkan ulat tersebut. Namun, hal itu tidak dihiraukan oleh Jumbo dan tetap melanjutkan penjelasannya. Miura yang semakin ketakutan kemudian berujar nande watashi no te de yarunda yo! 'mengapa kau memperagakannya dengan tangan ku!!' ketika Jumbo hendak mengaitkan umpan ke kail dengan menggunakan tangannya.

Tuturan nande watashi no te de yarunda yo merupakan tindak tutur melarang tidak langsung. Hal tersebut dapat dilihat dari ketidaksesuaian antara modus tuturan dengan maksud yang ingin disampaikan. Modus tuturannya adalah interogatif yang menyatakan sebuah pertanyaan (toikake no bun). Modus interogatif pada tuturan tersebut ditunjukkan dengan penggunaan kata tanya nande yang merupakan bentuk langsung dari pada doushite 'kenapa/ mengapa' (Kamermans, 2009: 352). Kalimat interogatif pada bahasa Jepang yang dibentuk dengan menyertakan kata tanya, seperti nani, doushite, doko, itsu, dan sebagainya yang diikuti dengan partikel penanda interogatif disebut dengan wh-questions (Hamano dan Tsujioka (2011: 66). Jenis pertanyaan ini dapat terjadi tanpa partikel penanda interogatif, seperti partikel $k a$, tetapi harus disertai dengan intonasi akhir yang tingggi. Jadi, dapat dilihat bahwa modus tuturannya adalah interogatif untuk menanyakan sebuah informasi. Namun, jika dilihat dari konteks tuturannya, penutur tidak hanya meminta sebuah informasi kepada mitra tutur. Secara tidak langsung penutur bermaksud melarang mitra tutur menaruh umpan di tangannya. Dari pemaparan tersebut, tuturan nande watashi no te de yarunda yo dapat digolongkan sebagai bentuk tindak tutur melarang tidak langsung.

Faktor yang melatarbelakangi penggunaan tindak tutur melarang tidak langsung pada data (3) adalah faktor tingkat keakraban, usia, dan jenis kelamin. Miura dan Jumbo tidak memiliki hubungan yang akrab karena mereka jarang bertemu. Hal tersebut menyebabkan Miura memilih untuk menyampaikan larangan secara tidak langsung (Mizutani dan Mizutani, 1987:3). Faktor selanjutnya yang juga memengaruhi tuturan tidak langsung penutur adalah faktor usia. Miura memiliki usia yang lebih muda daripada Jumbo sehingga mengharuskan Miura menggunakan tuturan tidak langsung kepada Jumbo (Mizutani dan Mizutani,1987: 4). Kemudian dilihat dari jenis kelamin, Miura merupakan seorang wanita. Okamoto (2004: 41-42) menyatakan bahwa wanita yang tidak menggunakan ragam bahasa yang santun atau formal dengan benar akan memperoleh penilaian yang tidak baik, dianggap malas, dan dibesarkan dengan tidak 
baik. Oleh sebab itu, wanita pada masyarakat Jepang diharapkan berbicara lebih sopan daripada laki-laki, seperti menggunakan bahasa yang santun atau ungkapan tidak langsung.

(4)

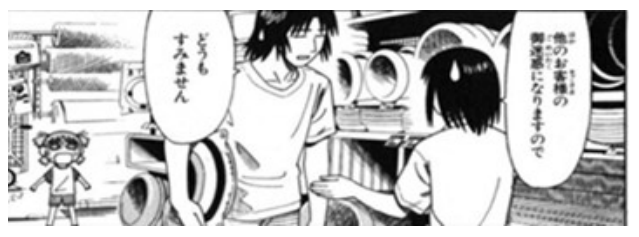

\begin{tabular}{|c|c|}
\hline こいわい & : 鳥よけない風船？ \\
\hline & なんだ ? これが怖いのか ? おまえ鳥か ? \\
\hline & ほーら。 \\
\hline よつば & : ぎやー。 \\
\hline こいわい & : ほら ほらー。 \\
\hline よつば & : ギャーツ。 \\
\hline 店員 & : ほかのお客様のご迷惑になりますので。 \\
\hline こいわい & : どうもすみません。 \\
\hline Koiwai & $\begin{array}{l}\text { :Tori yokenai fuusen? } \\
\text { Nanda? Kore ga kowai no ka? Omae tori ka? } \\
\text { Hoora. }\end{array}$ \\
\hline Yotsuba & : Gyaa. \\
\hline Koiwai & : Hora. Horaa. \\
\hline Yotsuba & : Gyaaa. \\
\hline Ten-in & : Hoka no okyaku sama no go meiwaku ni narimasu node. \\
\hline Koiwai & Doumo sumimasen \\
\hline
\end{tabular}

(Yotsubato volume 1, 2003:157)

$\begin{array}{ll}\text { Koiwi } & \text { : Balon pengusir burung? } \\ & \text { Apaan? Ini yang kamu takuti? Memangnya kamu burung? } \\ & \text { Nih. } \\ \text { Yotsuba } & \text { : Wuaa! } \\ \text { Koiwai } & \text { : Nih, nih! } \\ \text { Yotsuba } & \text { : Wuaa! } \\ \text { Pegawai toko } & \text { : Mohon maaf, perbuatan anda dapat mengganggu pelanggan toko } \\ & \text { lainnya. } \\ \text { Koiwai } & \text { : Maaf. }\end{array}$

Tuturan pada data (4) merupakan tuturan yang melibatkan pegawai toko (penutur) dengan Koiwai (mitra tutur) yang terjadi di dalam toko. Situasi pada saat itu, Koiwai 
menakut-nakuti Yotsuba dengan mendekatkan balon pengusir burung ke arah wajah Yotsuba sehingga membuatnya menjadi berteriak. Melihat kejadian itu, pegawai toko pun berujar hoka no okyaku sama no go meiwaku ni narimasu node 'mohon maaf, perbuatan anda dapat mengganggu pelanggan toko lainnya' kepada Koiwai untuk menghentikan keributan tersebut.

Tuturan hoka no okyaku sama no go meiwaku ni narimasu node merupakan tindak tutur melarang tidak langsung. Hal itu ditandai dengan ketidaksesuaian antara modus tuturan dengan maksud yang ingin disampaikan. Modus tuturannya adalah deklaratif, yaitu penutur menyampaikan suatu informasi kepada mitra tutur. Tuturan tersebut mengandung suatu informasi baru (genshou-byoushabun) yaitu penutur menyampaikan bahwa perbuatan mitra tutur dapat mengganggu kenyamanan pelanggan lain yang berada di toko. Nitta (dalam Sutedi, 2010:70) menyatakan bahwa genshou byoushabun adalah kalimat yang digunakan untuk menyampaikan suatu informasi baru. Namun, apabila dilihat dari konteks tuturannya, penutur bukan sekedar menyampaikan bahwa tindakan mitra tutur dapat mengganggu pelanggan yang lain, tetapi penutur juga bermaksud melarang mitra tutur agar tidak membuat keributan di dalam toko. Jadi, tuturan hoka no okyaku sama no go meiwaku ni narimasu node dapat dikategorikan sebagai bentuk tindak tutur melarang tidak langsung karena modus tuturannya berbeda dengan maksud yang ingin disampaikan.

Faktor yang melatarbelakangi penggunaan tindak tutur melarang tidak langsung pada data (4) adalah faktor hubungan sosial, tingkat keakraban, dan jenis kelamin. Dilihat dari hubungan sosial antara mereka, pegawai toko berstatus lebih rendah dari pada Koiwai. Hal tersebut dapat dilihat dari status penutur yang merupakan seorang pegawai toko sedangkan Koiwai adalah pelanggan toko. Sudah sewajarnya penutur yang berkedudukan lebih rendah menggunakan tuturan yang santun saat berbicara kepada mitra tutur yang berkedudukan lebih tinggi. (Mizutani dan Mizutani, 1987: 6). Kemudian, dilihat dari faktor tingkat keakraban, pegawai toko dan Koiwai tidak memiliki hubungan yang akrab karena mereka baru pertama kali bertemu. Mizutani dan Mizutani (1987:4) menyatakan bahwa ketika orang Jepang bertemu dengan seseorang untuk pertama kalinya, ia akan menggunakan tuturan yang santun. Selanjutnya dilihat dari segi jenis kelamin penutur, pegawai toko tersebut adalah seorang wanita. Okamoto 
(2004: 41) menyatakan bahwa wanita pada masyarakat jepang umumnya lebih banyak menggunakan ungkapan secara tidak langsung untuk mempersantun tuturannya.

\section{Simpulan}

Berdasarkan hasil analisis, bentuk tindak tutur melarang langsung ditandai dengan penggunaan ungkapan larangan $\sim n a, \sim c h a$ dame, dan $\sim$ naide. Dari ketiga ungkapan tersebut, $\sim n a$ memiliki nuansa larangan yang paling keras. Sementara bentuk tindak tutur melarang tidak langsung berupa larangan yang disampaikan dengan modus kalimat deklaratif, modus kalimat interogatif, dan modus kalimat imperatif.

Faktor yang berpengaruh pada tindak tutur melarang langsung adalah 1) tingkat keakraban, yaitu penutur dan mitra tutur memiliki hubungan yang akrab; 2) usia, yaitu penutur memiliki usia yang lebih tua daripada mitra tutur; 3) jenis kelamin, yaitu penutur dan mitra tutur memiliki jenis kelamin yang sama. Sementara faktor yang berpengaruh pada penggunaan tindak tutur melarang tidak langsung adalah: 1) tingkat keakraban, yaitu penutur dan mitra tutur tidak memiliki hubungan yang akrab; 2) usia, yaitu usia penutur lebih muda daripada mitra tutur; 3) hubungan sosial, yaitu penutur bersetatus lebih rendah daripada mitra tutur; 4) jenis kelamin, yaitu tindak tutur melarang tidak langsung lebih banyak diujarkan oleh kaum wanita untuk mempersantun tuturan dan untuk menunjukkan sisi feminimitasnya.

\section{Daftar Pustaka}

Gunarwan, Asim. 2007. Pragmatik Teori dan Kajian Nusantara. Jakarta: Universitas Atma Jaya.

Iori, Isao. 2000. Shokyu o Oshieru Hito no Tame no Nihonggo Bunpo Handobukku. Tokyo: Kurashiki Insatsu Kabushikigaisha.

Hamano, S dan Tsujioka, T. 2011. Basic Japanese: A Grammar and Workbook. USA: Routledge.

Kamermans, Michiel. 2009. An Introduction to Japanese Syntax, Grammar and Language [online]. Tersedia:http://www7a.biglobe.ne.jp/nifongo/conv/index.html. Lestari, Dwi Tiara. 2017. "Kesantunan Tindak Tutur Direktif Larangan dan Izin dalam Drama Jepang Kazoku Gemu” (Skripsi). Semarang: Universitas Dipenogoro.

Mahsun. 2007. Metode dan Teknik penelitian Bahasa. Jakarta: PT. Dunia Pustaka Jaya. Makino, S dan Tsutsui, M. 1984. A Dictionary of Basic Japanese grammar. Tokyo: The Japanese Times, Ltd.

Mizutani, O dan Mizutani, N. 1987. How to be Polite in Japanese. Tokyo: The Japanese Times, Ltd. 
Novitayanti, Ni Nyoman Yeni. 2011. "Bentuk Perintah dan Larangan dalam Komik Pafechikku Karya Nanaji Nagamu" (Skripsi). Denpasar: Universitas Udayana.

Okamoto, Shigeko. 2004. Japanese Language, Gender, and Ideology. Newyork: Oxford University Press.

Satria, Chandra Putra. 2018. "Penggunaan Ungkapan Perintah dan Larangan dalam Bahasa Jepang” (Skripsi). Semarang: Universitas Dipenogoro.

Sudaryanto. 1993. Metode dan Aneka Teknik Analisis Bahasa. Yogyakarta: Duta Wacana University Press.

Sutedi, Dedi. 2009. Dasar-Dasar Linguistik Bahasa Jepang. Bandung: Humaniora Utama Press.

Wijana, I Dewa Putu. 1996. Dasar-Dasar Pragmatik. Yogyakarta: Andi. 